\title{
Corrigendum
}

\section{Corrigendum to "Stress Cardiomyopathy Managed with Extracorporeal Support after Self-Injection of Epinephrine”}

\author{
Jeremy Bourenne $\mathbb{D}^{\mathbb{D}},{ }^{1}$ Raphaëlle Fresco, ${ }^{1}$ François Kerbaul, ${ }^{2}$ \\ Pierre Michelet, ${ }^{3}$ and Marc Gainnier ${ }^{1}$ \\ ${ }^{1}$ Réanimation des Urgences et Médicale, Assistance Publique Hôpitaux de Marseille, CHU la Timone 2, Aix-Marseille Université, \\ Marseille, France \\ ${ }^{2}$ Service d'Aide Médicale Urgente des Bouches du Rhône, CHU la Timone and UMR MD2, Aix-Marseille Université, Marseille, France
}

${ }^{3}$ Service d'Accueil des Urgences Adultes, Assistance Publique Hôpitaux de Marseille, CHU la Timone 2, Marseille, France

Correspondence should be addressed to Jeremy Bourenne; jeremy.bourenne@ap-hm.fr

Received 13 June 2018; Accepted 4 July 2018; Published 9 August 2018

Copyright (C) 2018 Jeremy Bourenne et al. This is an open access article distributed under the Creative Commons Attribution License, which permits unrestricted use, distribution, and reproduction in any medium, provided the original work is properly cited.

In the article titled "Stress Cardiomyopathy Managed with Extracorporeal Support after Self-Injection of Epinephrine" [1], the authors' names were reversed. The revised authors' list is shown above.

\section{References}

[1] B. Jeremy, F. Raphaëlle, K. François, M. Pierre, and G. Marc, "Stress cardiomyopathy managed with extracorporeal support after self-injection of epinephrine," Case Reports in Critical Care, vol. 2017, Article ID 3731069, 3 pages, 2017. 


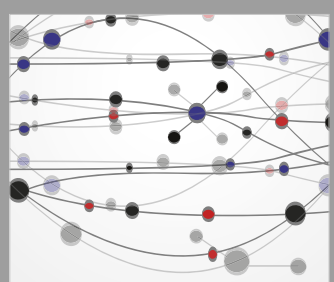

The Scientific World Journal
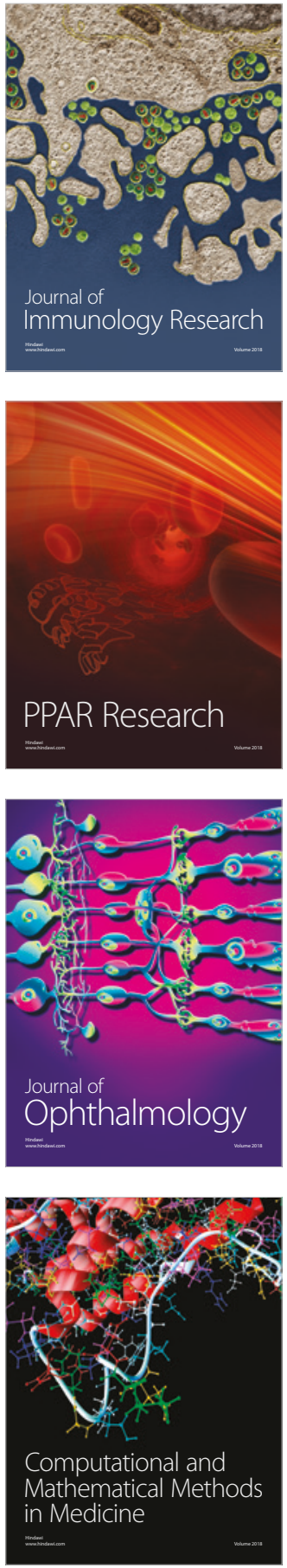

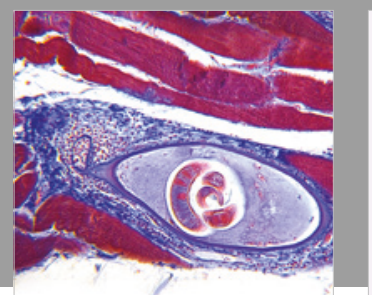

Gastroenterology Research and Practice

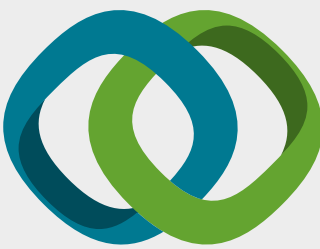

\section{Hindawi}

Submit your manuscripts at

www.hindawi.com
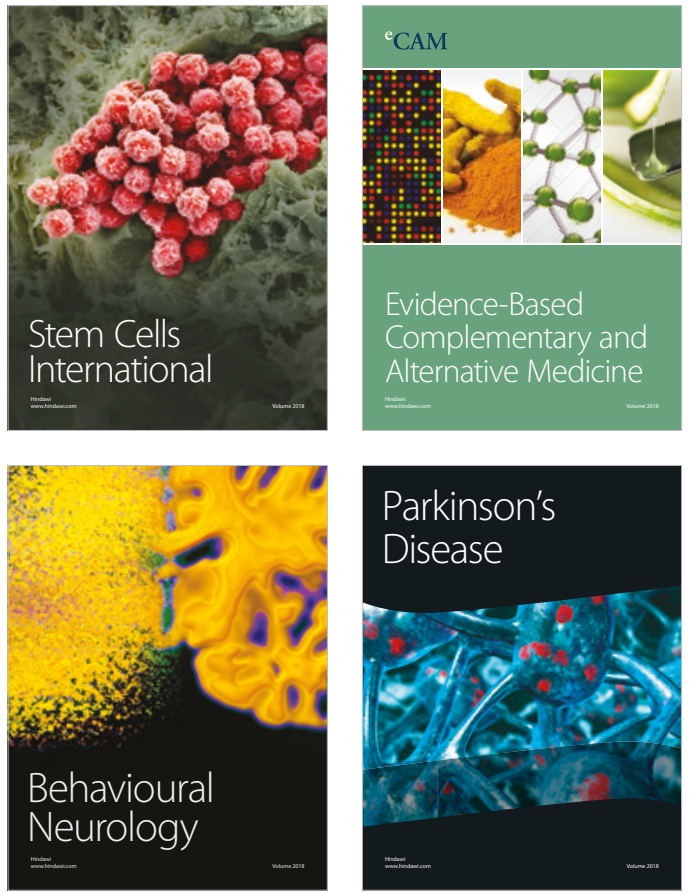

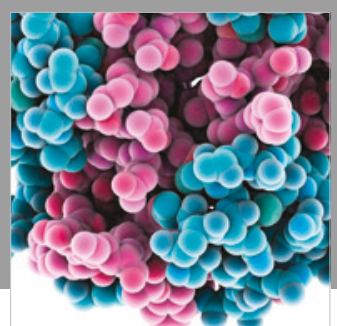

ournal of

Diabetes Research

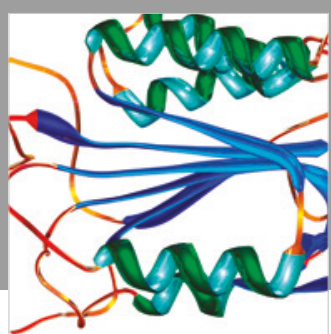

Disease Markers
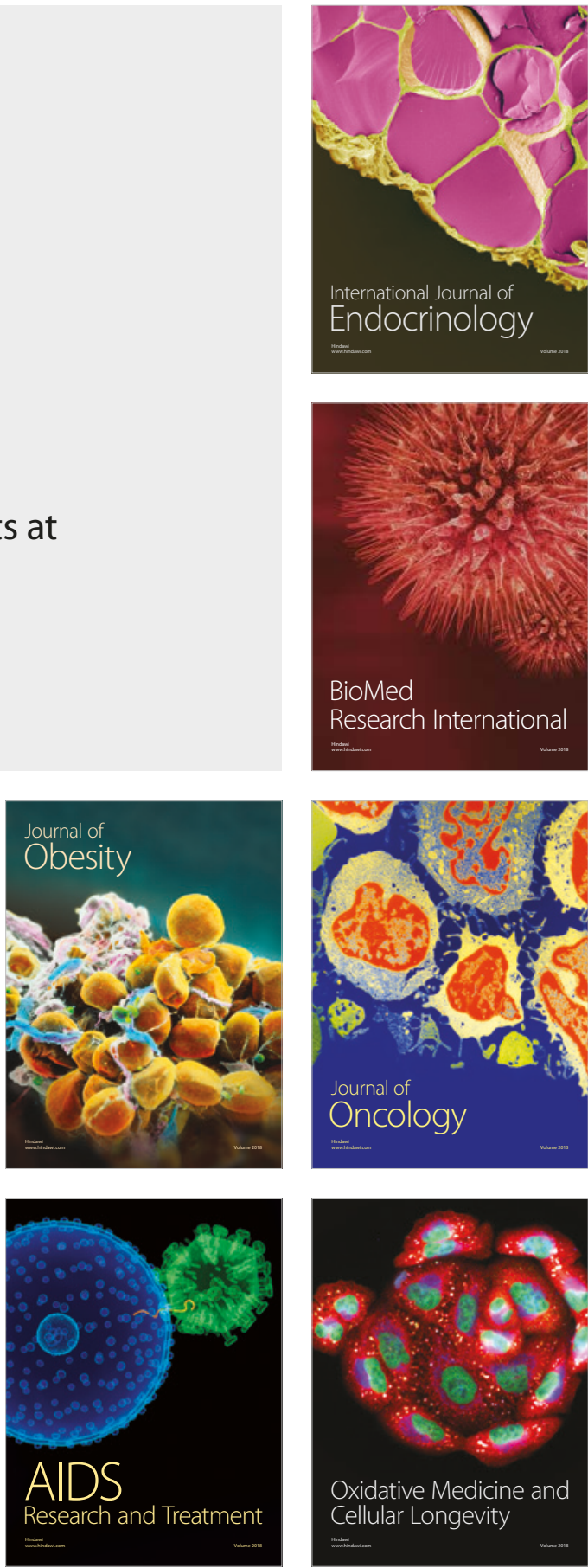